\title{
Inhibitory Effect of Bismuth Oxide Nanoparticles Produced by Bacillus licheniformis on Methicillin-Resistant Staphylococcus aureus Strains (MRSA)
}

\author{
Leila Firouzi Dalvand ${ }^{1}$, Farzaneh Hosseini ${ }^{1, *}$, Shahram Moradi Dehaghi ${ }^{2}$, Elham Siasi Torbati ${ }^{1}$ \\ ${ }^{1}$ Department of Microbiology, North Tehran Branch, Islamic Azad University, Tehran, Iran \\ ${ }^{2}$ Department of Chemistry, North Tehran Branch, Islamic Azad University, Tehran, Iran
}

"Corresponding author: Farzaneh Hosseini, Department of Microbiology, North Tehran Branch, Islamic Azad, Tehran, Iran. Tel: +98-9123472441, Fax +9877009848, E-mail: fa_hosseini@iau-tnb.ac.ir

Received: 17 Nov. 2017; $\quad$ Revised: 17 Jul. 2018; $\quad$ Accepted: 31 Jul. 2018; $\quad$ Published online: 12 Dec. 2018

\begin{abstract}
Background: Based on the increase in antibiotic-resistant pathogens, it is necessary to have various effective compounds, so as to prevent its proliferation of these pathogens. For this purpose, nano-materials such as bismuth oxide nanoparticles can be used.

Objectives: The aim of this study was to produce bismuth oxide nanoparticles by Bacillus licheniformis PTCC1320 and to determine the antimicrobial effects on methicillin-resistant Staphylococcus aureus species compared with some antibiotics. Materials and Methods: In this study, 200 bacterial samples were collected from hospitalized patients with burn infections from the Burn Rescue Hospital,Tehran. Thereafter, 65 strains of methicillin-resistant Staphylococcus aureus were identified by their phenotype and genotype. A total of $92 \%$ of identified strains with the highest resistance to antibiotics were isolated. Bismuth oxide nanoparticles were synthesized by Bacillus licheniformis PTCC1320. FTIR spectroscopy, X-ray diffraction, and scanning electron microscopy (SEM) were used to analyze the extracellularly produced nanoparticles. Finally, the antibacterial properties of nanoparticles produced on the biofilm of some pathogens were examined.

Results: In the present study, cube-shaped bismuth oxide nanoparticles were formed in the size range of 29-62 nm. They were found to have antimicrobial activity on $16 \%$ of the isolated Staphylococcus aureus strains. The FTIR results showed the vibrational frequencies of bismuth oxide at $583,680,737$, and $1630 \mathrm{~nm}$. The XRD results also confirmed the structure of nanoparticles. Compared with antibiotics such as Ciprofloxacin, bismuth oxide nanoparticles had less affectivity on this resistant hospital pathogen. Increasing the concentration of bismuth oxide nanoparticles, increased its antimicrobial effect and decreased bacterial growth rate.

Conclusion: Compared with heavy metals, bismuth nanoparticles have very low antibacterial effects. Considering this feature, the use of less antibiotics can be achieved with bismuth nanoparticles in the treatment of infections, thereby reducing antibiotic resistance.

Key words: Bacillus licheniformis, Methicillin-Resistance Staphylococcus aureus, Nanoparticles
\end{abstract}

\section{Background}

The Gram-positive bacterium, Methicillin-resistant Staphylococcus aureus (MRSA), exhibits resistance to the beta-lactam antibiotics through horizontal gene transfer and natural transmission (1). The antibiotic resistance of S.aureus strains has become a global warning problem, resulting to failure in the treatment of bacterial infections, thus endangering the patient's life and increasing the cost of treatment. This microorganism is regarded as a commonly occurring infectious disease which cause the formation of biofilms in damaged tissue and patients hospitalized with catheters (2).

MRSA is responsible for common infections in hospitals. Patients with weak immune systems, Open injuries, diabetes disease, catheters diseases and also, the elderly are exposed to more risk. MRSA strains are the main cause of sepsis in hospitals around the world $(3,4)$. PCR-based search of the mecA gene is the most accurate method for MRSA detection (5). Microorganisms are linked to various surfaces through the Exo-polysaccharide Matrix (EPS) to create antibiotic resistance. In fact, the EPS matrix protects microbial

Copyright (C 2018 The Author(s); Published by National Institute of Genetic Engineering and Biotechnology. This is an open access article, distributed under the terms of the Creative Commons Attribution-NonCommercial 4.0 International License (http://creativecommons.org/licenses/ by-nc/4.0/) which permits others to copy and redistribute material just in noncommercial usages, provided the original work is properly cited. 
cells from high concentrations of antibiotics which leads to chronic infections despite antibiotic treatments. Different groups of bacteria form biofilms which cause very important problems in medicine and industry. The growing microbial cells in biofilms are physiologically different from their planktonic counterparts (6). In 2010, the American community urged the discovery of new drugs to fight antibiotic-resistant microorganisms, stating that one of the promising strategies for overcoming microbial resistance is by making use of nanoparticles (7). Microorganisms use the organic and inorganic resources in the environment to perform their metabolism and critical processes. When exposed to metal ions, microorganisms accumulate these materials inside or on the cell walls through different processes. This accumulation often results in the production of particles that are packaged in nanoparticles (8). Inorganic nanoparticles are used in various medical fields to diagnose and treat diseases (9). In recent years, nanotechnology has yielded amazing growth and development in nanoparticles-based medicine which has been a revolution in the treatment of diseases by potent and less toxic drugs (10). In 2013, Nazari et al. synthesized bismuth by Serratia marcescens (11) but in this study, Bismuth oxide nanoparticles were produced using Bacillus licheniformis PTCC 1320 strain for the first time and its antimicrobial effect was investigated on methicillin-resistant Staphylococcus aureus biofilms. There has been no study on bismuth oxide nanoparticles produced by Bacillus licheniformis PTCC 1320 but bismuth has been synthesized by Serratia marcescens (11).

\section{Objective}

The aim of this study was to produce bismuth oxide nanoparticles using Bacillus licheniformis by a green method, and the investigation of its antimicrobial effect on methicillin-resistant Staphylococcus aureus (MRSA) isolated from hospitalized burn patients .

\section{Materials and Methods}

\subsection{Preparation of Bacillus licheniformis PTCC 1320 With Bismuth Nitrate Resistance}

Bacillus licheniformis PTCC1320 was obtained from the Iranian Research Organization for Science and Technology, Tehran, Iran.. The bacteria was cultured on a bismuth sulfide agar medium (MERCK, Germany) and incubated at $30{ }^{\circ} \mathrm{C}$ for $24 \mathrm{~h}, 0.2 \% \mathrm{w} / \mathrm{v}$ bismuth nitrate solution was added to the nutrient agar (MERCK, Germany). The standard Bacillus strain was grown at 30 ${ }^{\circ} \mathrm{C}$ for $24 \mathrm{~h}$.

\subsection{Synthesis of Bismuth Oxide Nanoparticles}

Bismuthnitrate $\mathrm{Bi}\left(\mathrm{NO}_{3}\right)_{3} .5 \mathrm{H}_{2} \mathrm{O}$ with a final concentration of 485 g.L.-1 was prepared in distilled water. In the present study, 0.003, 0.055, 0.03 and $0.05 \mathrm{M}$ of Bismuth nitrate were prepared for use in subsequent syntheses. The bacterial strains were incubated in $50 \mathrm{~mL}$ of a saltfree broth, with MacFarlend half-concentration at 35 ${ }^{\circ} \mathrm{C}$ for $24 \mathrm{~h}$. This was followed by centrifugation for 20 min at $8000 \times \mathrm{g}$ and $4{ }^{\circ} \mathrm{C}$, the biomass was discared. The supernatant was studied for the extracellular production of bismuth oxide nanoparticles. The bismuth nitrate solution was added to the supernatant with a $10 \% \mathrm{~V} / \mathrm{V}$ ratio and incubated at the same temperature. After color change, the sediment was separated by centrifugation at $8000 \times \mathrm{g}$ in $20 \mathrm{~min}(11,12)$.

To ensure that other additional items were completely removed, the sediments were washed three times with $0.9 \% \mathrm{w} / \mathrm{v} \mathrm{NaCl}$ solution. The precipitate was incubated for 2 to 3 days at $40{ }^{\circ} \mathrm{C}$. Then, in order to carry out calcination of the nanoparticles, the resulting precipitate was placed in a furnace for $2 \mathrm{~h}$ at $550^{\circ} \mathrm{C}(13)$. Bismuth oxide nanoparticles were then analyzed using FTIR spectroscopy, X-ray diffraction (XRD) and scanning electron microscopy (SEM).

\subsection{Sample Collection of Hospitalized Patients}

Bacterial samples (200 samples) were collected from wound infections of burn patient injuries from Motahari Hospital in Tehran, starting from October, 2016 to July, 2017. Sampling was performed using a cotton swab impregnated in normal saline. In order to identify methicillin-resistant Saureus, the specimens were cultured in the Mannitol Salt agar medium (MERCK, Germany) and incubated at $37^{\circ} \mathrm{C}$ for $48 \mathrm{~h}$. Then, sixtyfive strains of Saureus resistant to antibiotic-resistant methicillin were identified.

\subsection{DNA Extraction of Methicillin-Resistant Staphylococcus aureus}

After the morphological identification of strains and biochemical tests (Gram staining, catalase, coagulase, DNase, and growth on mannitol salt agar media), gene sequencing was used for genus identification (14). Single bacterial colonies were inoculated into a 5 mLsuitable culture medium (LB), shaken for $24 \mathrm{~h}$ at $37{ }^{\circ} \mathrm{C}$ and $120 \mathrm{rpm}$. Genomic DNA was extracted using Genom DNA extraction kit, according to the manufacturer's instructions (Cinnagen, Iran). The extracted specimen was stored at $-20^{\circ} \mathrm{C}$.

\subsection{PCR-Based Genotyping Assays}

Forward and reverse primers with a length of $140 \mathrm{bp}$ were designed for the molecular detection of mecA (15) 
Table 1. The sequences of primers used in this study.

\begin{tabular}{lccc}
\hline Gene & Forward primer & Reverse primer & Lenght (bp) \\
\hline$m e c A$ & AACAGGTGAATTATTAGCACTTGTAAG & ATTGCTGTTAATATTTTTTGAGTTGAA & $140 \mathrm{bp}$ \\
\hline
\end{tabular}

using PCR (Table 1). The PCR process was done to a final volume of $25 \mu \mathrm{L}$ PCR by mixing $18 \mu \mathrm{L}$ of double distilled water, $2.5 \mu \mathrm{L}$ of PCR buffer (10X), $1 \mu \mathrm{L}$ of dNTP $(10 \mathrm{mM}), 1 \mu \mathrm{L}$ of Forward primers $(10 \mathrm{PmoL})$ and $1 \mu \mathrm{L}$ Reverse Primers (10 PmoL), $1 \mu \mathrm{L}$ of genomic DNA (100 ng) and finally, $0.5 \mu \mathrm{L}$ of enzyme Taq Polymer (1U.100 $\left.\mu \mathrm{L}^{-1}\right)$. PCR was performed with an initial denaturation step $94{ }^{\circ} \mathrm{C}$ for $5 \mathrm{~min}$, followed by 30 cycles of $94{ }^{\circ} \mathrm{C}$ for $1 \mathrm{~min}, 55^{\circ} \mathrm{C}$ for $1 \mathrm{~min}$ and $72{ }^{\circ} \mathrm{C}$ for $2 \mathrm{~min}$, with a final extension at $72{ }^{\circ} \mathrm{C}$ for $10 \mathrm{~min}$. Then samples were run on $1 \%$ agarose gel based on TAE buffering conditions at $80 \mathrm{v}$ for $1 \mathrm{~h}$. To determine the size of the amplified fragment, a $100 \mathrm{bp}$ marker was used. The gel was then stained with ethidium bromide solution for $10 \mathrm{~min}$. The gel was visualized using a UV illuminator.

\subsection{Resistance Study of Strains to Antibiotics}

In order to investigate the lack zone of growth and determine sensitivity to antibiotics, all strains were concentrated on the Muller Hinton Agar culture medium (MERCK, Germany).

Then by using the Kirby-Bauer method, according to the Clinical Laboratory Standards Institute (CLSI) table, sensitivity to the antibiotics of microorganisms was investigated. Antibiotics such as ciprofloxacin $(5 \mu \mathrm{g})$, vancomycin $(30 \mu \mathrm{g})$, gentamicin $(10 \mu \mathrm{g})$, ceftazidime $(30 \mu \mathrm{g})$, cefalotin $(50 \mu \mathrm{g})$, tetracycline (30 $\mu \mathrm{g})$, methicillin $(5 \mu \mathrm{g})$, rifampin $(5 \mu \mathrm{g})$ were used (16).

\subsection{Disc Diffusion Method for Studying the Antimicrobial Properties of Bismuth Oxide \\ Nanoparticles}

In order to investigate the antimicrobial effect of the bismuth oxide nanoparticles produced by $B$. licheniformis PTCC 1320, $1 \mathrm{~mL}$ of methicillin-resistant Staphylococcus bacteria was added to the Muller Hinton Agar (MERCK, Germany); then it was cultivated with a sterile swab. Blank disks were prepared with a diameter of $6 \mathrm{~mm}$. Thirty sterile blank disks were kept for $1 \mathrm{~h}$ to complete the absorption in different dilutions of bismuth oxide nanoparticles i.e. 100, 300, 600, 900, 1200 and $1500 \mathrm{ppm}$. Then they were placed at $40{ }^{\circ} \mathrm{C}$ for $1 \mathrm{~h}$ to dry. They were placed in a muller Hinton agar culture medium containing the mentioned pathogens, with the appropriate distance from each other and the edge of the plate. Finally, the plates were incubated at $37^{\circ} \mathrm{C}$ for $24 \mathrm{~h}$. After which the halo zone diameter was measured (17).

\subsection{MIC (Minimum Inhibitory Concentration)}

To examine the minimum inhibitory concentration (MIC) for bacterial growth using serial dilutions were prepared from the solutions of Bismuth oxide nanoparticles, a different volume of Mueller-Hinton broth medium (MERCK, Germany), and inoculated bacterial suspension. MRSA with the concentration of $1.5 \times 10^{8} \mathrm{CFU} . \mathrm{mL}^{-1}$ were added separately to $20 \mathrm{~mL}$ cultures in five conical flasks $(50 \mathrm{~mL})$. The cultures were incubated at $37{ }^{\circ} \mathrm{C}$ with shaking at $150 \mathrm{rpm}$ for $24 \mathrm{~h}$. Growth rates and bacterial concentrations were observed, and Broth Dilution Method were used (18).

\subsection{Biofilm Formation}

From single culture colonies of methicillin-resistant S.aureus strains and the liquid control in the LB medium with the standard 0.5 Mac Farland at a wavelength of $630 \mathrm{~nm}$ for each sample was set. Then, $100 \mu \mathrm{L}$ of each sample and the control strain were added to 6 parallel pits in a 96-well polystyrene microtiter plate. Also, the LB medium (MERCK, Germany) with $1 \%$ glucose in a 6-well row was used as control. The samples were incubated at $37{ }^{\circ} \mathrm{C}$ for $48 \mathrm{~h}$. The $0.01 \mathrm{M}$ isotonic potassium phosphate buffer was added to each well with sterile saline ( $\mathrm{pH}$ 7.5). Then about 200 microliters of pure methanol was added to each well and placed at room temperature for $10 \mathrm{~min}$. The crystalline violet color was then added at $1 \%(\mathrm{~W} / \mathrm{V})$ and kept for $20 \mathrm{~min}$ at room temperature. After evacuation and washing with water, 33\% glacial acetic acid was added. Each well was analyzed using an ELISA reader at $630 \mathrm{~nm}$. Each test was repeated three times (19).

\subsection{Antimicrobial Characteristics of Bismuth Oxide Nanoparticles}

Ciprofloxacin $0.5 \mathrm{mg} . \mathrm{L}^{-1}$ was filtered then the effect of $1500 \mathrm{ppm}$ bismuth oxide nanoparticles and Ciprofloxacin on antibiotic resistant isolates strains from hospitalized patients was investigated. For this purpose, 96 microtiter plates containing live biofilms were used to investigate the antimicrobial properties of bismuth oxide nanoparticles and incubated at $37{ }^{\circ} \mathrm{C}$ for $24 \mathrm{~h}$. Then the biofilms OD were evaluated. Luria- 
Bertani (LB) culture medium OD was analyzed without biocide and with monoclonal bacteria as control $(12,17)$.

\section{Results}

\subsection{Biosynthesis of the Bismuth Oxide Nanoparticles ( $\left.\mathrm{Bi}_{2} \mathrm{O}_{3} \mathrm{NPS}\right)$}

After the cultivation of B.licheniformis PTCC 1320 for $24 \mathrm{~h}$, the colonies appeared to be black with metal lining. At the $0.005 \mathrm{M}$ concentration of bismuth oxide, the supernatant was changed (from yellow to brown) after 7 days and it was investigated for the presence of nanoparticles (Fig. 1).

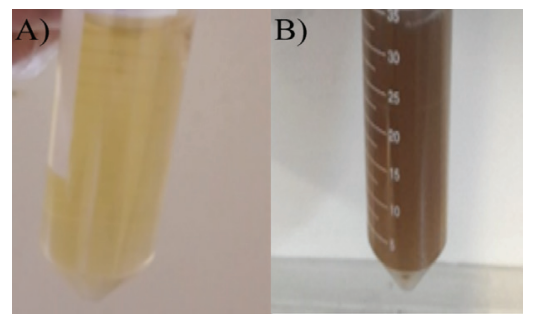

Figure 1. Change of colors after 7 days of incubation. A: culture supernatant with bismuth nitrate, B: supernatant mixed with $\mathrm{Bi}_{2} \mathrm{O}_{3} \mathrm{NPs}$.

\subsection{Identification of Microorganism}

Sixty-five isolated bacteria from hospitalized patients with burn infections was identified following to the routine biochemical and morphological examinations. Results showed that the isolated strain relates to the methicillin-resistance Staphylococcus aureus species. The isolated strain was cocci-shaped and Grampositive bacterium. As well the bacterium was found to be Catalase, coagulase, DNase positive and Oxidase negative. Yellow colonies growth on mannitol salt agar (14).

In this study, PCR amplification showed a length of about $140 \mathrm{bp}$ of the product, MRSA strains were positive for the presence of mec $A$ gene with the highest antibiotic resistance. (Fig. 2).

The SEM results showed that the bismuth oxide nanoparticles produced had a uniform and cube-shaped morphology (Fig. 3). Average particle size of $\mathrm{Bi}_{2} \mathrm{O}_{3}$ was about $45 \mathrm{~nm}$.

B.licheniformis strain 1320 has also been shown to produce extracellular BiNPs with corresponding crystalline surfaces. ; According to the Debye Scherrer formula, they had an average size of $47.47 \mathrm{~nm}$.

All nanoparticles produced were smaller than 100 $\mathrm{nm}$, as it is clearly shown in the SEM image (Fig.3).

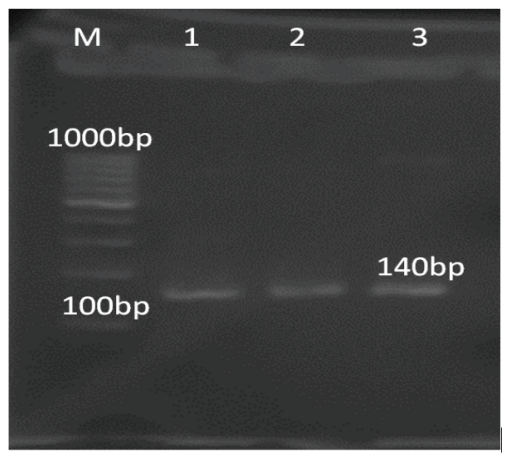

Figure 2. Electrophoresis of mecA 140 bp genes on $1 \%$ agarose gel. Lane 1-3: PCR product of mecA gene (140bp); M: 100 bp DNA size marker.

According to the Debye Scherrer formula, the average size was $47.47 \mathrm{~nm}$. All nanoparticles produced were smaller than $100 \mathrm{~nm}$, as it is clearly shown in the SEM image. Assignments of Miller indices (hkl) are presented in Table 2, a family of lattice planes was determined by three integers $\mathrm{h}, \mathrm{k}$, and $\mathrm{l}$, the Miller indices and denotes the family of orthogonal planes, which is the basis of the reciprocal lattice vectors.

X-ray diffraction patterns and FTIR spectrum demonstrated that the purified NPs consisted of Bi-O$\mathrm{Bi}$ in wavelengths of $583 \mathrm{~cm}-1,737 \mathrm{~cm}-1$ stretching vibrational of $\mathrm{O}-\mathrm{Bi}-\mathrm{O}$, and $1630 \mathrm{~cm}-1$ stretching of Bi-O and $3437 \mathrm{~cm}-1$ stretching vibrational of $\mathrm{O}-\mathrm{H}$ group for hydroxyl functional group in surface of $\mathrm{Bi} 2 \mathrm{O} 3$ (Figs. 4 and 5).

\subsection{Antibacterial Activity}

The highest antibiotic sensitivity rates were reported

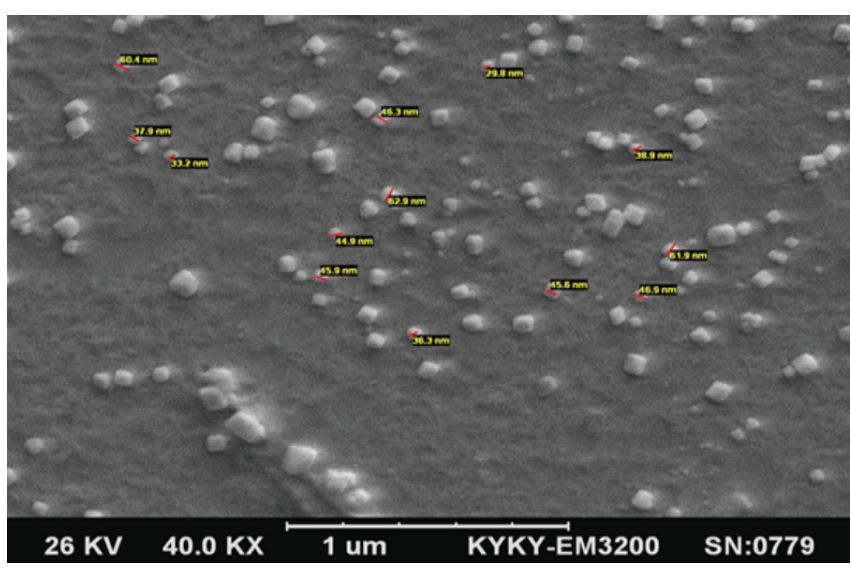

Figure 3. SEM image of Bismuth oxide nanoparticles produced by B.licheniformis Strain 1320. 
Firouzi Dalvand L et al.

Table 2. XRD Results showing the compliance of Bismuth Oxide with the Standard peaks.

\begin{tabular}{cccccc}
\hline & Observed 2 $\theta$ & Observed Intensity & (hkl) & Standard 2 $\theta$ & Standard Intensity \\
\hline \multirow{2}{*}{ XRD major peak of } & 27.33 & 100 & -121 & 27.38 & 100 \\
$\mathrm{Bi}_{2} \mathrm{O}_{3}$ & 33.17 & 70 & -202 & 33.23 & 36 \\
& 52.37 & 87 & -322 & 52.38 & 12 \\
\hline \multicolumn{2}{c}{ Crystal size by Sherrer equation } & 69 & -223 & 46.29 & 18 \\
\hline \multicolumn{2}{c}{ Particle size by SEM } & & $47(\mathrm{~nm})$ & \\
\hline
\end{tabular}

hk1: Miller indices

for ciprofloxacin $85 \%$ while the lowest was reported for methicillin (8\%), rifampin (4\%) and vancomycin (3\%). The highest concentration of $\mathrm{Bi}_{2} \mathrm{O}_{3} \mathrm{NPs}(1500 \mathrm{ppm})$, showed antibacterial activity Approximately similar to gentamycin $(15 \%)$ and cephalothin $(15 \%)$. Figure
6 shows the percentage of MRSA strains sensitive to antibiotic and bismuth oxide nanoparticles.

The results showed that the produced nanoparticles with a concentration of $1500 \mathrm{ppm}$ and the inhibitory effect of $17 \mathrm{~mm}$ had the highest inhibitory effect on the

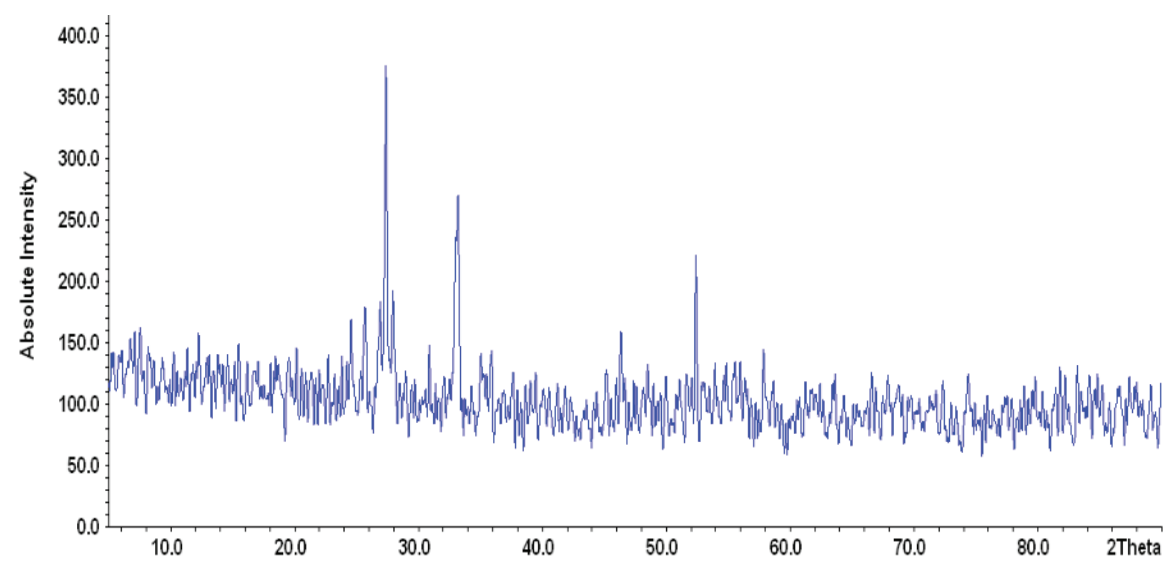

Figure 4. X-ray diffraction patterns derived from bismuth oxide nanoparticles produced by Bacillus licheniformis PTCC 1320.

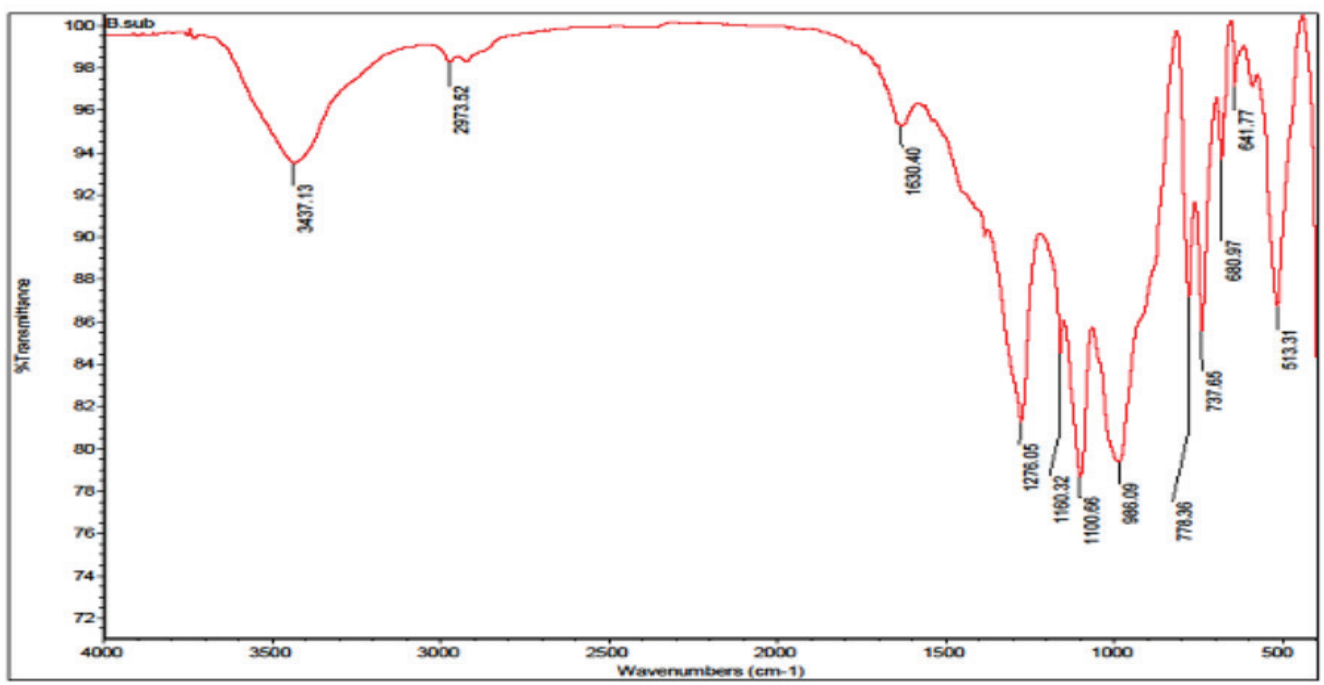

Figure 5. FTIR spectrum of $\mathrm{Bi}_{2} \mathrm{O}_{3}$ nanoparticle synthesized by Bacillus licheniformis. 


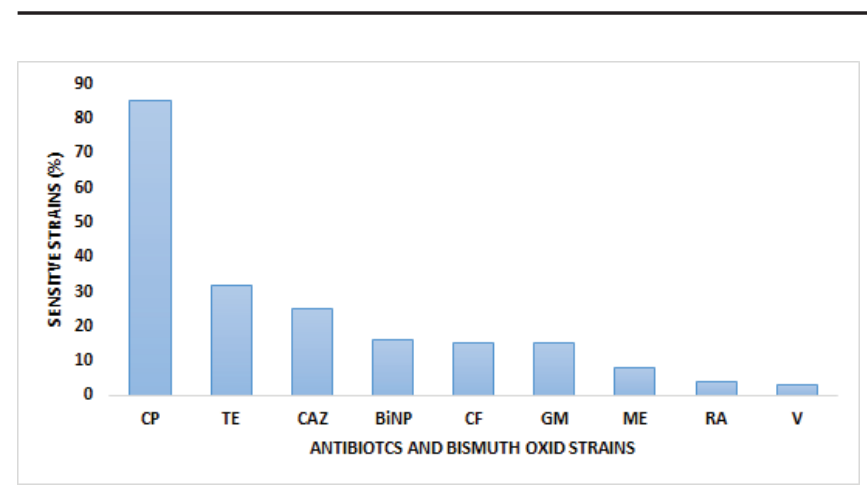

Figure 6. The sensitivity of MRSA strains to patients hospitalized with burns. (CP) ciprofloxacin, (TE) tetracycline, (CAZ) ceftazidime, (BiNP) bismuth nanoparticles, (GM) gentamicin, (CF) cephalothin, (ME) methicillin, (RA) rifampin, (V) vancomycin.

MRSA strains, while the concentration of $100 \mathrm{ppm}$ with the lowest inhibitory effect recorded the least effect.

\subsection{Biofilm Formation}

The average absorption of the Staphylococcus aureus biofilm was recorded at $1.557 \mathrm{~nm}$. Then, in the presence of ciprofloxacin and bismuth oxide nanoparticles, OD was read with an average of 0.65 and 1.055 for methicillin-resistant S.aureus, respectively. The OD of the negative control was 0.04 , and the positive one was 1 . Bismuth oxide nanoparticles had an inhibitory effect on $16 \%$ biofilm of the pathogen samples while in planktonic conditions, all sixty-five strains were inhibited by increasing the nanoparticles concentration. It could be concluded that biofilm formation produced drug resistance in the bacteria.

\section{Discussion}

Nanotechnology is a new field with many uses in medicine, for example the treatment and diagnosis of disease. Nanoparticles have antibacterial activity like that of silver, copper oxide, bismuth and selenium. The advantages of inorganic nanoparticles include high surface-volume ratio, different shapes, unique structural forms and nanoparticle sizes which interact with bacteria. These characters among nanoparticles and antimicrobial agents are the main difference and are capable of reducing the danger of developing antibacterial resistance. For instance, the crystalline structure of bismuth nanoparticles can react with biological systems, including bacteria, fungi and viruses. One of the most important characteristics of nanoparticles is that they reduce the probability of antimicrobial resistance development (20).

The extracellular synthesis mechanism of nanoparticles using microorganisms is yet to be fully understood and their exact mechanism of action against biological systems are yet to be completely elucidated. Several studies have reported that a positive charge on the metal ion is acute for antibacterial activity, permitting for electrostatic absorption between the negative charge on the bacterial cell membrane and the positive burden on the nanoparticle. Bismuth oxide is used in the production of glass, ceramic products and catalyst in the oxidation of hydrocarbons (21).

In this study, S.aureus was used to study the effect of bismuth oxide nanoparticles produced extracellularly through the use of B.licheniformis PTCC 1320, with a change in the color of the supernatant from yellow to brown, as the selected strain, the green method was selected to form the nanoparticle and its formation was confirmed by infrared spectroscopy, XRD and SEM. The results of this study indicate that cubical and uniform $\mathrm{Bi}_{2} \mathrm{O}_{3} \mathrm{NPs}(29-62 \mathrm{~nm})$ were produced using B. licheniformis. These NPs had effective antibacterial property against MRSA but compared with antibiotics, bismuth oxide nanoparticles had a low effect on this pathogen. The MIC of bismuth oxide nanoparticles for bacterial growth inhibition was 1500 ppm. Compared to heavy metals, bismuth nanoparticles have very low toxic effects. Considering this feature, it may be possible to reduce the concentration of antibiotics and the use of bismuth oxide nanoparticles in the treatment of infections, results in decreasing antibiotic resistance. To determine if bismuth oxide nanoparticles can interfere with MRSA biofilm formation, the antibiofilm activity of these nanoparticles was evaluated. The observation of antibiofilm activity of $\mathrm{Bi}_{2} \mathrm{O}_{3} \mathrm{NPs}$ against the MRSA showed the bactericidal activity of the nanoparticles against $16 \%$ pathogenic bacteria and nanoparticles have antibacterial activity against the planktonic form of MRSA in high concentration. The total bactericidal activity has been determined in different concentrations of the $\mathrm{Bi}_{2} \mathrm{O}_{3} \mathrm{NPs}$ but at lower concentration the inhibition rate was low.

Hernandez-Delgadino et al. studied the inhibitory effect of chemically synthesized bismuth zerovalent nanoparticles on the formation of Streptococcus mutans biofilms. Growth inhibition of these bacteria was observed (20). On the other hand, Nazari et al. studied the antimicrobial activity of bismuth nanoparticles produced by S.marcescence (isolated from the Caspian Sea) on Helicobacter pylori. Bismuth nanosized particles were smaller than $100 \mathrm{~nm}$ when synthesized. They showed that bismuth nanoparticles had a antimicrobial activity on these strains (11), which is similar to this study Which indicates the antibacterial 
activity of bismuth nanoparticles.

In 2015 and 2016, Delijou et al. (22) and Sarangadharan et al.(23), respectively, synthesized silver nanoparticles, Shivashankarappa

synthesized Cds nanoparticle while Thakur et al. (25) synthesized gold nanoparticles through the use of $B$. licheniformis in 7-31, 3-170, 20-40, and $45 \mathrm{~nm}$ particle sizes, respectively. This study showed the ability of B.licheniformis to synthesize $\mathrm{Bi}_{2} \mathrm{O}_{3} \mathrm{NPs}$ in the range of 29-62 $\mathrm{nm}$ size. The results of earlier studies and the present study indicate the potential of B.licheniformis bacteria in the synthesis of nanoparticles in good range and different sizes of nanoparticles perhaps for use of different doses of precursor or type of precursor. To the our knowledge, this is the first report of bismuth oxide nanoparticles synthesized by the B.licheniformis.

Biofilm isolates of the isolated MRSA strains from patients were studied using PCR molecular methods and the effect of the above nanoparticles on the planktonic and biofilm bacteria was evaluated and compared with the antimicrobial effect of ciprofloxacin antibiotic. This study showed that Bismuth oxide nanoparticles were effective in increasing the concentration againest planktonic form, but their anti-biofilm activity was low when compared with ciprofloxacin The size and shap of nanoparticle may influence against bacteria (22). The advantages of the bacterium to the production of Bismuth oxide nanoparticles are high availability, lowcost production, and GRAS microorganism.

The results of this study showed that, compared with antibiotics, bismuth oxide nanoparticles had a low effect on this pathogen. Compared to heavy metals, bismuth nanoparticles have very low toxic effects. Considering this feature, it may be possible to reduce the concentration of antibiotics and the use of bismuth oxide nanoparticles in the treatment of infections, results in decreasing antibiotic resistance.

At the end, it is suggested that, based on studies, bacteria such as S.marcescence and B.licheniformis are capable of synthesizing bismuth nanoparticles, which can be used to synthesize other nanoparticles in the industry and medicine to battle bacterial resistance, and also, the quantity and time of production of nanoparticles are compared.

Producing metal nanoparticles using the bacteria, the mechanism of conversion of metal ions into nanoparticles is not understood completely. Therefore, it is suggested that this mechanism would be investigated, this might lead to more optimized methods of producing these nanoparticles.

Biosynthesis of bismuth nanoparticles with Bacillus bacteria and investigating their abilities in medical and pharmaceutical industries can be evaluated. Overall, the experimental results suggest that these nanoparticles could be an interesting alternative to fight the infections underlying planktonic form. But further experiments are required for use in the human body.

\section{Acknowledgments}

The authors are grateful to Dr. Mehdi Pooladi from the department of biology, Science and Research Branch, Islamic Azad University, Tehran, Iran and $\mathrm{Mr}$ Mohammad Ali Tavakoli for his help, equipment and valuable guidance.

\section{References}

1. Gurusamy KS, Koti R, Toon CD, Wilson P, Davidson BR. Antibiotic therapy for the treatment of methicillin-resistant Staphylococcus aureus (MRSA) infections in surgical wounds. J Cochrane Database Syst Rev. 2013;20(8): CD010427. doi: 10.1002/14651858.CD009726. pub2

2. Elzahraa Akram F, El-Tayeb T, Abou-Aisha1 K, El-Azizi M. A combination of silver nanoparticles and visible blue light enhances the antibacterial efficacy of ineffective antibiotics against methicillin-resistant Staphylococcus aureus (MRSA). J Ann Clin Microbiol Antimicrob. 2016; 15:48. doi: 10.1186/ s12941-016-0164-y

3. Dumyati G, Stone ND, Nace DA, Crnich CJ, Jump RL. Challenges and Strategies for Prevention of Multidrug-Resistant Organism Transmission in Nursing Homes. $J$ Curr Infect Dis Rep. 2017;19(4):18. doi: 10.1007/s11908-017-0576-7

4. Sganga G, Tascini C, Sozio E, Carlini M, Chirletti P, Cortese $\mathrm{F}$, et al. Focus on the prophylaxis, epidemiology and therapy of methicillin-resistant Staphylococcus aureus surgical site infections and a position paper on associated risk factors: the perspective of an Italian group of surgeons. World J Emerg Surg. 2016;11:26. doi:10.1186/s13017-016-0086-1

5. Murray, Patrick.2007. Manual of clinical microbiology. Washington, D.C: ASM Press. doi: 10.1086/524076

6. Karatan E, Watnick P. Signals, regulatory networks, and materials that build and break bacterial biofilms. J Microbiol Mol Biol Rev. 2009;73(2):310-347. doi: 10.1128/MMBR.00041-08

7. Hajipour MJ, Fromm KM, Ashkarran AA, Jimenez de Aberasturi $\mathrm{D}$, de Larramendi IR, Rojo T, et al. Antibacterial properties of nanoparticles. J Trends Biotechnol. 2012;30(10):499-511. doi: 10.1016/j.tibtech.2012.06.004

8. Prasad K, Jha AK, Kulkarin AR. Lactobacillus assisted synthesis of titanium nanoparticles. J Nanoscale Res Lett. 2007;2(5):248250. doi:10.1007/s11671-007-9060-x

9. Colvin VL. The potential environmental impact of engineered nanomaterials. J Nat Biotechnol. 2003; 21(10):1166-1170. doi: $10.1038 / \mathrm{nbt} 875$

10. 10. Drummond DC, Noble CO, Guo Z, Hong K, Park JW, Kirpotin DB. Development of a Highly Active Nanoliposomal Irinotecan Using a Novel Intraliposomal Stabilization Strategy. $J$ Cancer Res. 2006; 66(6):3271-3277. doi: 10.1158/0008-5472

11. Nazari P, Dowlatabadi-Bazaz R, Mofid MR, Pourmand MR, Daryani NE, Faramarzi MA, et al. The Antimicrobial Effects and Metabolomic Footprinting of Carboxyl-Capped Bismuth Nanoparticles Against Helicobacter pylori. J Appl Biochem Biotechnol. 2014; 172(2):570-579. doi: 10.1007/s12010-013- 
0571-x

12. Vidhya LD, Roshmi T, Rintu TV, Soniya E V, Jyothis M, Radhakrishnan EK. Extracellular synthesis of silver nanoparticles by the Bacillus strain CS 11 isolated from industrialized area. 3 Biotech. 2014;4(2): 121-126. doi:10.1007/s13205-013-0130-8

13. Jing M, Jia C, Liangsheng Q, Juanqin X. Effect of Different Calcination Temperatures on the Structural and Photocatalytic Performance of $\mathrm{Bi}_{-} \mathrm{TiO}_{2} / \mathrm{SBA}-15$. Int J Photoenergy. 2013; 2013: 10. doi: 10.1155/2013/875456.

14. Montazeri EA, Khosravi AD, Jolodar A, Ghaderpanah M, Azarpira S. Identification of methicillin-resistant Staphylococcus aureus (MRSA) strains isolated from burn patients by multiplex PCR. Burns. 2015;41(3):590-594. doi: 10.1016/j.burns.2014.08.018.

15. Tarek Z, Karima B, Salem IE, Omayma H, Amina B. Molecular investigation of antibiotic resistance genes in methicillin resistant Staphylococcus aureus isolated from nasal cavity in pediatric service. J African J Microbiol Res. 2013;7(34), 4414-4421. doi:10.5897/AJMR2013.5778

16. Nicole MB, Tam TV, Timothy AM, Steven AM, David MW. Comparison of Cefoxitin and Oxacillin Disk Diffusion Methods for Detection of mecA-Mediated Resistance in Staphylococcus aureus in a Large-Scale Study. J Clin Microbiol. 2009 ;47(1):217219. doi: 10.1128/JCM.01506-08

17. Doudi M, Naghsh N, Setorki M. Comparison of the effects of silver nanoparticles on pathogenic bacteria resistant to betalactam antibiotics (esbls) as a prokaryote model and Wistar rats as a eukaryote model. J Med Sci Monit Basic Res. 2013;19:103110. doi: 10.12659/MSMBR.883835

18. Bland MV, Ismail S, Heinemann JA, Keenan JI. The action of Bismuth against Helicobacter pylori Mimics but is not caused by intracellular iron deprivation. J Antimicrob Agents Chemother 2004; 48(6):1983-1988. doi: 10.1128/AAC

19. Fujiwara T, Hoshino T, Ooshima SH. Differential and quantative analyses of mRNA expression of glucosyltransferases from Streptococcus mutans MT8148. J Dent Res. 2002;81(2):109-113. doi. 10.1177/0810109

20. Hernandez-Delgadino R, Velasco-Arias D, Diaz D, Arevalo-Niño $\mathrm{K}$, Garza-Enriquez M, De la Garza-Ramos MA, et al. Zero valent bismuth nanoparticles inhibit Streptococcus mutans growth and formation of biofilm. Int J Nanomedicine. 2012;7:2109-2113. doi: $10.2147 /$ IJN.S29854

21. Reem SA. Structural and optical properties of nanostructured bismuth oxide. Int Let Chem, Physic Astronomy. 2014; 34: 64-72. doi:10.1852/www.scipress.com/ILCPA.34.64

22. Deljou A, Goudarzi S. Green Extracellular Synthesis of the Silver Nanoparticles Using Thermophilic Bacillus Sp. AZ1 and its Antimicrobial Activity Against Several Human Pathogenetic Bacteria. Iran J Biotech. 2016;14(2): 25-32. doi:10.15171/ ijb. 1259

23. Sarangadharan S, Nallusamy S. Biosynthesis and Characterization of Silver Nanoparticles Produced by Bacillus licheniformis. Int J Pharma Med Biol Sci. 2015;4(4):236-239. doi: 10.18178/ijpmbs.

24. 24. Shivashankarappa A, Sanjay KR. Study on Biological Synthesis of Cadmium Sulfide Nanoparticles by Bacillus licheniformis and Its Antimicrobial Properties against Food Borne Pathogens. JNN. 2015;3(1):6-15. doi:10.12691/nnr-3-1-2.

25. ThakurRK, Shirkot P, Verma A. Exploration of Microbial Diversity of Himalaya Region for Gold Nanoparticles Synthesizing Bacteria. Int J Curr Microbiol App Sci. 2017; 6(8): 2191-2210. doi.10.20546/ijcmas. 